\title{
A Comprehensive Analysis of Solvation Number, Internal Pressure and Equivalent Conductance of Some Imidazolium Salts
}

\author{
Seethalakshmi $\mathbf{K}^{1}$, Jasmine Vasantha Rani $\mathbf{E}^{2}$ \\ PG \& Research Department of Physics, Seethalakshmi Ramaswami College, Tiruchirapalli-2, Tamilnadu, India
}

\begin{abstract}
Thermodynamic and electrochemical properties of salts find extensive application in characterizing physico-chemical properties. This paper deals with the thermodynamic and electrochemical behaviour of solutions of some imidazolium salt solutions. Measurement of density, viscosity and ultrasonic velocity leads to the determination of internal pressure which tells about the interaction between molecules and ions. Specific conductance values are also measured for studying ionic behaviour of the solutions. All the measurements are carried out for various concentrations of the solutions in the temperature range from $278.15 \mathrm{~K}$ to $328.15 \mathrm{~K}$. These parameters provide the sufficient information about the interaction between the ions and molecules of solvent.
\end{abstract}

Keywords: Ultrasonic velocity, Density, Viscosity, Internal Pressure, Equivalent Conductance

\section{Introduction}

Ultrasonics is an interesting field of study which makes an effective contribution to many areas of human endeavor. In the recent years, many attempts have been made in the field of physical acoustics and ultrasound on solids, liquids and gases .Ultrasonic velocities and derived thermodynamic parameters are of considerable interest in understanding the nature and strength of various intermolecular interactions occurring in the solution. In the present case, work undertaken is to study the thermo acoustical behavior of some imidazolium salt solutions in solvent reveals the structural interaction taking place in the solutions.

\section{Experimental}

Here, the samples are purchased from Sigma Aldrich chemicals, USA with high purity (99\%) and hence used without any further purification. The solutions are prepared with five different molalities. Density of the solution is measured using $25 \mathrm{ml}$ specific gravity bottle, using thermostatic bath with a compressor unit with an accuracy of $0.001 \mathrm{gm} / \mathrm{cc}$. Canon Fenske viscometer was used for the viscosity measurements. Variable path interferometer having a frequency of $2 \mathrm{MHz}$ with an overall accuracy of $0.1 \%$ was used for velocity measurements. A constant temperature bath (digitalized) was used to circulate water through the double-walled measuring cell of steel containing the experimental solution at the desired temperature $(278.15 \mathrm{~K}$ to $328.15 \mathrm{~K})$.

\section{Computation}

Using the experimentally measured values, the following thermo dynamical parameters are computed using the standard formulae ${ }^{[1]}$

(i) Solvation number $\quad n_{\mathrm{s}}=n_{f} / n_{i}\left[1-\beta_{\text {soln }} / \beta_{\text {solv }}\right]$

(ii) Internal Pressure $\Pi_{\mathrm{i}}=\mathrm{bRT}(\mathrm{k \eta} / \mathrm{U})^{1 / 2} *\left(\rho^{2 / 3} / \mathrm{M}_{\mathrm{eff}}^{7 / 6}\right)$ atms

(iii) Equivalent conductance $\Lambda_{\mathrm{C}}=\mathrm{k}^{\prime} \mathrm{V} \mathrm{cm} \mathrm{ohm}^{-1}$ where

$\beta_{\text {solv }}$-the compressibility of a solvent

$\beta_{\text {soln }}$ the compressibility of the solution

$\mathrm{R}$ - gas constant $\left(8.314 \times 10^{7}\right)$

$\mathrm{T}$ - temperature

b - cubic constant(2)

$\mathrm{k}$ - constant equal to $4.28 \times 10^{9}$

$\eta$ - viscosity of the solution in poise

$\mathrm{U}$ - ultrasonic velocity in $\mathrm{cm} / \mathrm{sec}$

$\rho$ - density of the solution in $\mathrm{gm} / \mathrm{cc}$.

$\mathrm{M}_{\text {eff }}$ - effective molecular weight of the solution in $\mathrm{gm}$

$\mathrm{k}^{\prime}$ - specific conductance

$\Lambda_{\mathrm{C}}$ - the equivalent conductance

\section{Results and Discussion}

\subsection{Solvation number}

Solvation number clearly represents the solvation of solute in solvent causes interactions giving rise to increase the solubility of solute.

In hmimCl, solvation number is positive at high temperatures $(308.15 \mathrm{~K}-328.15 \mathrm{~K})$, this positive values of solvation number suggest that the compressibility of the solutions are less compressible than that of solvent ${ }^{[2]}$. It is shown in figure. Solvation number values are decreased with rise in concentration at all temperatures. The decrease in solvation number with increase in concentration may be due to the lack of the solvent molecules for all the ions or occur as of ion pairing in the solution ${ }^{[3]}$.

In bzmimCl, solvation number is positive at high temperatures and it is negative at low temperatures for all concentrations. This behavior suggests that solution is more compressible than solvent above room temperature. It supports that there is a weak solute-solvent interaction 


\section{International Journal of Science and Research (IJSR) \\ ISSN (Online): 2319-7064 \\ Index Copernicus Value (2015): 78.96 | Impact Factor (2015): 6.391}

between solute and solvent. The variation with respect to temperature and concentration are shown in the figure.

In the case of dmimCl, it is found that at $278.15 \mathrm{~K}-298.15 \mathrm{~K}$ shows a negative solvation number for all the molalities, whereas positive solvation number is observed for other temperatures (Fig). Positive values of solvation in solutions suggest that compressibility of the solutions is less compressible than that of solvent. Negative values of solvation number at lower temperatures emphasize that solutions are more compressible than that of solvent.

Solvation Number

Figures- 4.1.1-4.1.6
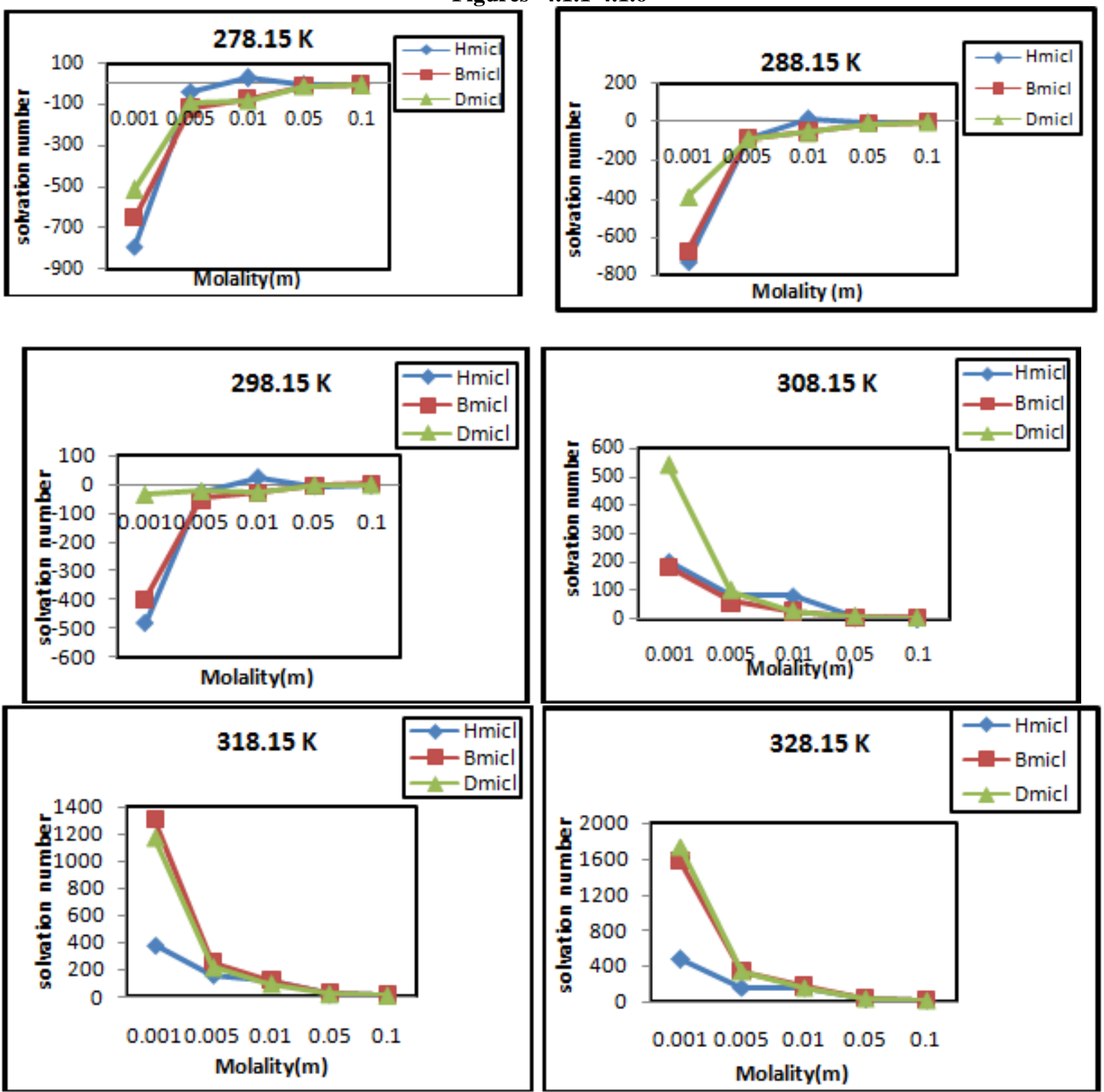

\subsection{Internal pressure}

Internal pressure of a solution is a single factor which appears to vary with intermolecular interaction namely, quantum mechanical forces of dispersion and dielectric forces, solute- solvent interactions which play an important role in the transport properties of solution. The interaction depends upon the solvent and solute structure and the temperature.

In $\mathrm{hmimCl}$, the internal pressure values are increasing with concentration for all temperatures and also decreasing with temperatures.(Fig). An increase in internal pressure indicates the orientation of the solvent molecules around the hmimCl

\section{Volume 6 Issue 1, January 2017 www.ijsr.net}




\section{International Journal of Science and Research (IJSR) \\ ISSN (Online): 2319-7064 \\ Index Copernicus Value (2015): 78.96 | Impact Factor (2015): 6.391}

of the molecules, which may be brought about by increasing in magnitude of interactions ${ }^{[6]}$ (Fig). This behavior supports that there is a strong solute-solvent interaction. The internal pressure increases with increase in concentration indicate the association through hydrogen bonding. It shows the increasing magnitude of interaction between the solute and solvent ${ }^{[7]}$.

Internal pressure

Figures- 4.2.1-4.2.6
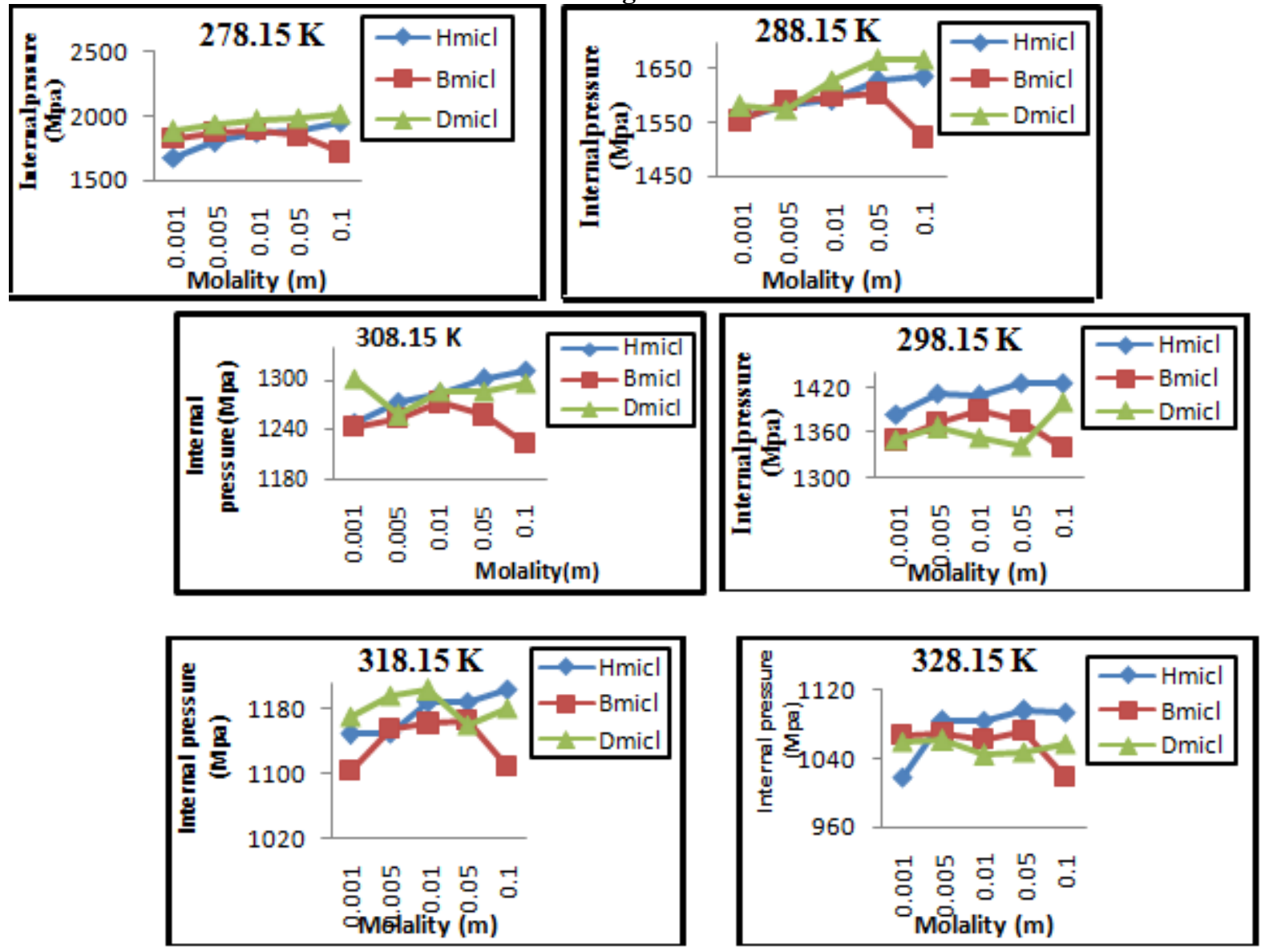

\subsection{Equivalent conductance:}

The variation of equivalent conductance with concentration of the solutions is shown in figures. In the case of all electrolyte solutions, the equivalent conductance is found to be high at low concentrations, decreasing exponentially with concentration and increasing with temperature. Variation of equivalent conductance is found to be very small at higher concentrations.

The decrease in equivalent conductance with increase of internal pressure is noticed in all systems.

$\operatorname{hmim~} \mathrm{Cl}>$ bzmim $\mathrm{Cl}>\mathrm{dmimCl}$

It is interesting to note that the molecular weights of the above salts are increasing in the same order. It may be explained that the mobility of the ions depends upon their size $^{[8]}$.

The present study of equivalent conductance of solutions can be summarized as

- $\Lambda_{\mathrm{C}}$ is very high at lower concentrations and decreases exponentially with concentration ${ }^{[9]}$.

- $\Lambda_{\mathrm{C}}$ increases with increase in temperature ${ }^{[10]}$.

- $\Lambda_{\mathrm{C}}$ decreases with increase in internal pressure ${ }^{[11]}$.

The very same results are also reported by $\mathrm{Mao}^{[12]}$ et al., in the conductivity study.

These are due to

(i) The increase of viscosity and therefore reduction of mobility of the charge carriers

(ii) Reduction of the number of the charge carriers due to aggregate formation ${ }^{[13]}$.the latter becomes dominant at higher concentration, thus leading to a strong decrease of conductivity ${ }^{[14]}$. 
International Journal of Science and Research (IJSR)

ISSN (Online): 2319-7064

Index Copernicus Value (2015): 78.96 | Impact Factor (2015): 6.391

Equivalent Conductance $\Lambda_{\mathrm{C}}$

Figures-4.3.1-4.3.6

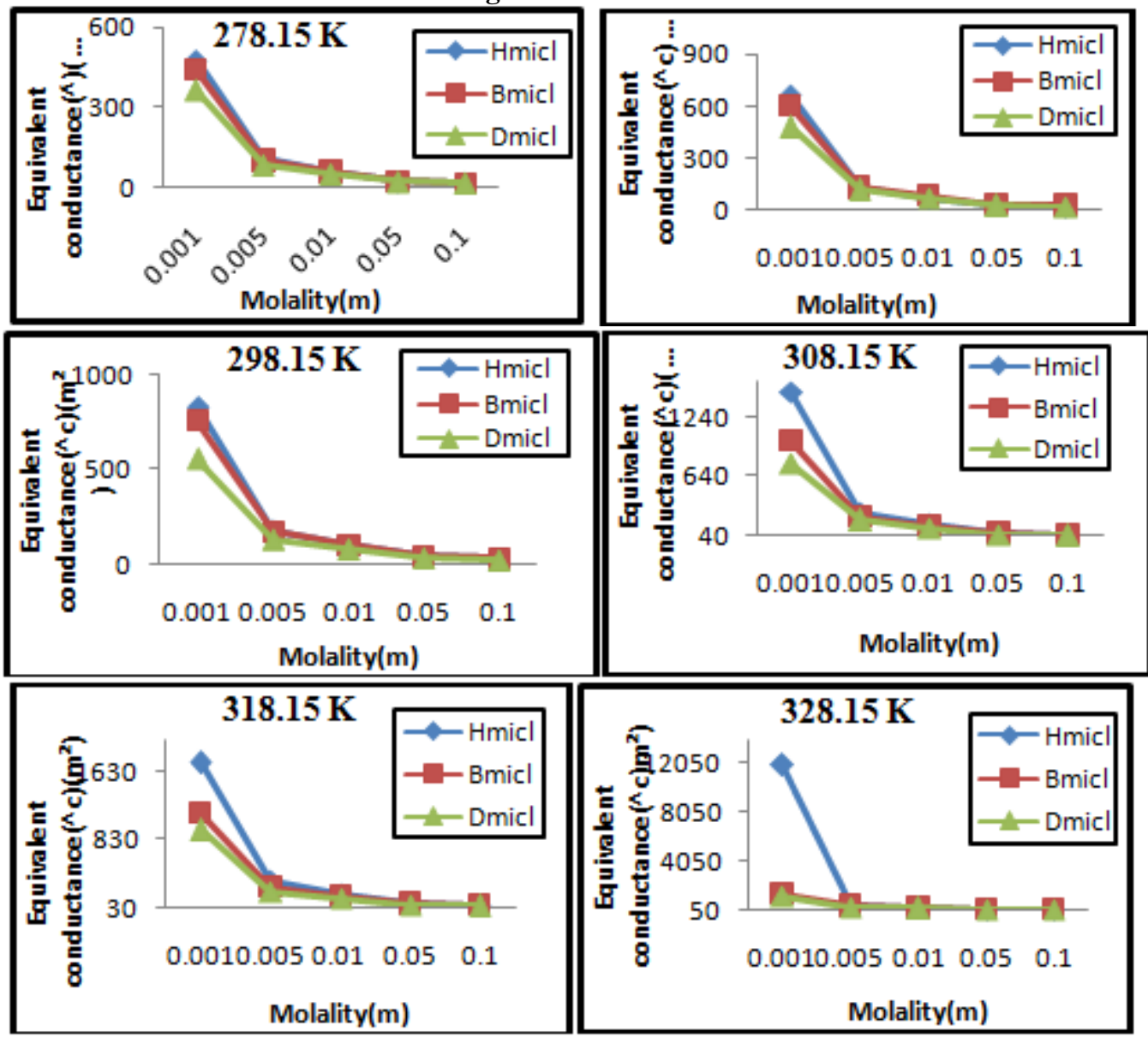

\section{Conclusion}

The positive and negative values of solvation number throw light on the solute-solvent interactions in the coordination spheres. The relationship between the equivalent conductance, internal pressure and molality is analyzed. The results obtained again reveal the significance of internal pressure in the study of liquid systems. The effects of varying the temperature of the system are also reported. The mobility's of the ion increases with temperatures, an increase in $\Lambda_{\mathrm{C}}$ at higher temperatures.

\section{References}

[1] Suryanarayana C.V. J. Acou .Soc. India 7(1979) 131136.

[2] Virendra Kumar, Panikar Y, Palafox M A,et.al., Indian journal of pure and applied physics 48 (2010) 85.

[3] Thomas Cottineau, Mireille Richard-Plouet, Jean-Yves Mevellec, Luc Brohan, The Journal of Physical Chemistry C (2011).

[4] Xiujie Ji, Bowen Cheng, Jun Song and Chao Liu, Acta Crystal (2010).

[5] Moore, W.J., "Physical Chemistry", 4th edn., Longmans, London (1965).

[6] Daya nand, Dr. Vijay singh, Int J Chem Res, 2 (2011) 47.

[7] Alamelumangai G and Santhi N, International Letters of Chemistry, Physics and Astronomy 5 (2014) pp 124 $-133$.
[8] Ji-Guang Li, Yu-Feng Hu, Chuan-Wei Jin, Hong-Da Chu, Xiao-Ming Peng, Ying-Guo Liang, Journal of Solution Chemistry 12 (2010) pp $1877-1887$.

[9] Gopal R, Hussain M M, J. Indian Chem Soc., 40 (1963) 981.

[10] Antropov L I, "Theoretical electrochemistry" Mir Publishers $1^{\text {st }}$ Edition (1972) pp $114-116$.

[11] JasmineVasantha Rani E, Padmavathy R J.Acous.Soc. Ind. (2005) 207.

[12] Mao G \& Zhu A. Iran. J. Chem. Chem. Eng. 321 (2013).

[13] Wu B, Liu W.W, Zhang Y.M, Wang H.P, Do We Chem. Eur. J, 15 (2009) 1804.

[14] Farid I .EI Dossoki, Journal of Solution Chemistry 42 1 (2013) pp 125 - 135.

\section{Volume 6 Issue 1, January 2017 www.ijsr.net}

